\title{
Velhice e Casamento, Vivências e Visões ${ }^{1}$
}

\author{
Marlene Neves Strey ${ }^{2}$ \\ Flora Maria Bojunga de Mattos ${ }^{3}$ \\ Patrícia Flores de Medeiros ${ }^{4}$ \\ Liana Weber Cardoso 5 \\ Daniela Canazaro de Mello ${ }^{6}$ \\ Michele Stefani ${ }^{7}$ \\ Sabrina Braga Torres ${ }^{8}$
}

\section{Resumo}

Este trabalho, apresentado no XXVII CONGRESSO INTERAMERICANO DE PSICOLOGIA, em Caracas, em junho de 1999, é parte de uma pesquisa mais ampla, que está sendo realizada pelo Grupo de Pesquisas e Estudos Sobre o Envelhecimento (PSICOGERON), dentro do Campo da Psicologia Social, no Programa de Pós-Graduação da Faculdade de Psicologia da Pontifícia Universidade Católica do Rio Grande do Sul (PUCRS). São apresentados os resultados de uma investigação com trinta pessoas idosas, casadas, de 60 a 81 anos, com nível médio e superior de escolaridade, que responderam a um questionário sobre casamento, amor, sexo e família. Os resultados apontam para uma conformidade aos estereótipos ainda vigentes sobre papéis para homens e mulheres, formação de família e satisfação conjugal.

Palavras-Chave: velhice; casamento.

\section{Abstract}

This paper, presented at the XXVII INTERAMERICAN CONGRESS OF

\footnotetext{
${ }^{1}$ Trabalho apresentado no XXVII Congresso Interamericano de Psicologia em Caracas, Venezuela, de 27 de junho a 2 de julho de 1999 .

${ }^{2}$ Coordenadora do grupo de pesquisa Trabalho e Relações de Gênero, Pós-Graduação da Faculdade de Psicologia, PUCRS, Doutora em Psicologia Social. E-mail: streymn@music.pucrs.br ${ }^{3}$ Psicóloga Clínica e Mestre em Psicologia pela PUCRS.

${ }^{4}$ Psicóloga Clínica e Mestranda de Psicologia Social e da Personalidade na PUCRS, bolsista da CAPES. ${ }^{5}$ Socióloga, formada pela Universidade do Vale dos Sinos (UNISINOS).

${ }^{6}{ }^{7}$ Alunas do curso de Psicologia - PUCRS - bolsistas de iniciação científica.

${ }^{8}$ Terapeuta ocupacional, formada no Instituto Porto Alegre (IPA).
}

Estud. interdiscip. envelhec., Porto Alegre, v.2, p.23-34, 1999. 
PSYCHOLOGY, in Caracas, june 1999, is part of a survey in progress by a research and studies about aging group, in the field of Social Psychology (Graduate Program in the Psychology Faculty of Pucrs). The purpose os this study was to verify some aspects about elderly views about marriage, love, sex and family through a questionnaire constructed over previous interviews. The sample was composed by elderly of both sexes, between 60 and 81 years old. Results point out to the conformity to current stereotypes about women and men, social roles, family and marital satisfation.

Key-Words: aging, marriage.

\section{Introdução}

As questões relativas à velhice têm recebido destaque nos últimos anos tanto nos meios acadêmicos como na mídia em geral em todo o mundo. Este fenômeno é preocupante para o Brasil, considerado um país jovem, mas que conta atualmente com mais de 12 milhões de pessoas idosas, tendo a perspectiva de, em 2025, ser o sexto país no mundo em número de pessoas acima de 60 anos (IBGE, 1997).

O casamento é uma instituição que está sofrendo transformações, assim como a família, ou a sua organização, está em pleno processo de reestruturação. É nesse campo de novos modos de pensar e agir, que as pessoas idosas casadas vivenciam a sua vida a dois e participam aceitando ou não essas mudanças.

Uma das características da cultura ocidental capitalista judaico-cristã é o casamento monogâmico heterossexual formal e ritual com a finalidade, entre outras, de regrar o sexo, a moral e, eticamente, a vida do casal, estabelecendo um tipo imaginário de comportamento recíproco. $\mathrm{O}$ casamento implica em uma transmissão não só do patrimônio material, mas principalmente valorativo, através da educação e da convivência (Vainfas, 1986). Nesse contexto passamse as regras comportamentais, as preferências estéticas, os conceitos e preconceitos, as relações de poder, enfim, toda a produção da sociedade através das normas e valores peculiares a cada grupo ou camada social.

Sugerem alguns estudos que as taxas de mortalidade variam segundo o estado civil. Os homens casados e as mulheres casadas ou com companheiras/ os possuem taxas menores de mortalidade, enquanto os homens divorciados e 
as mulheres divorciadas possuem taxas mais altas do que os/as que estão viúvos/ as e solteiros/as. Conclui Veras (1994) que a companhia é um fator positivo para o prolongamento da vida na velhice.

Em relação à vida sexual, deve-se considerar as décadas de 1920 e 1930, época de nascimento de nossa população idosa, quando predominava uma moral rígida junto aos ideais religiosos, impedindo a manifestação da sexualidade. A vida sexual estava voltada unicamente para a vida privada, sendo proibida a conversa sobre esse tema no âmbito público. Além do mais, sempre foi comum a confusão entre sexualidade e genitalidade.

A genitalidade, embora relacionada à sexualidade, diz mais respeito às questões biológicas e fisiológicas dos órgãos sexuais. O envelhecimento pode ocasionar a diminuição da potência sexual, produzindo uma lentificação da ereção e da ejaculação no homem. A mulher, com a corrente percepção de que o climatério-menopausa é uma doença, traz consigo um mal-estar. Fisiologicamente o que acontece na velhice é um ressecamento vaginal, mas não o desaparecimento do desejo.

A sexualidade, por sua vez, é uma função do ser humano que está sempre presente. Não se é assexuado por ter-se 80 anos, como também não se é por ter cinco ou 25 anos. A sexualidade é uma linguagem, uma forma de comunicação; tem a ver com o amor, com a ternura e com os afetos.

Não se pode comparar a velhice com um modelo de juventude, precisamos pensar essa etapa de uma outra maneira com as suas específicas possibilidades. A sexualidade deve e pode manter-se na velhice.

A idéia neo-liberal, vigente em certos âmbitos das ciências sociais e humanas, é de que tanto a mulher como o homem acabam sendo responsabilizados individualmente por inserção, ou não, nos novos avanços sociais, econômicos e tecnológicos. Compromete-se o indivíduo por ter ou não ter, uma velhice saudável, passando-se a idéia de que a pessoa é a única responsável por seu bem-estar. Isenta-se com isso a sociedade como um todo, negando-se a influência cultural na constituição da identidade do indivíduo.

\section{A Imagem Social do Envelhecimento}

Se levarmos em conta as idéias veiculadas, principalmente pelos meios 
de comunicação social, de que é necessário combater a velhice através de cremes rejuvenecedores, exercícios e massagens para manter a musculatura ágil e firme, cirurgias estéticas para corrigir a ação do tempo, as tinturas para cobrir os cabelos brancos e muitos outros artifícios para retardar o declínio da juventude, podemos vir a pensar o fenômeno do envelhecimento como algo problemático. No entanto, pode-se entender esse processo como algo não problemático, ainda que o seja social e politicamente. Se configura aí uma tensão que se estende às estruturas e aparatos utilizados para a sua definição e para " ( . . . ) a solução do problema" (Rodríguez, 1994).

Quando se valoriza algo como negativo, obviamente tudo o que lhe diga respeito, aparentemente, só apresentará desvantagens. Isso é bastante verdadeiro quando se contrasta o processo de envelhecimento em uma sociedade onde se louva continuamente a juventude, principalmente no que diz respeito às mulheres.

O que, principalmente, define as mulheres atualmente no mundo ocidental capitalista (embora suspeitemos que não apenas aí)? Ser bela (Wolf, 1991) e ser mãe (Lima; Strey, 1999). O que acontece, então, quando beleza, juventude e potencialidade de ser mãe se vão? Sobra pouco e, talvez, as pessoas mais velhas sejam percebidas como já não servindo para nada nesse mundo pragmático. E, na medida em que, ocasionalmente, vão adoecendo, além de "não servirem para nada", passam também para a categoria das que atrapalham e perturbam a vida das demais pessoas (Inserso/Instituto de la Mujer, 1994).

Esse estado de coisas certamente não é fenômeno isolado e circunscrito a determinados grupos sociais. Provavelmente seja uma representação social bastante generalizada e que atinge duramente as pessoas idosas, que também podem pensar o mesmo sobre si mesmas e sua condição, com a decorrente baixa da auto-estima, confiança no futuro e motivação para viverem o melhor possível.

A problemática em discussão atinge proporções maiores na medida em que sabemos que a expectativa de vida das pessoas está aumentando cada vez mais, como já viu-se anteriormente, principalmente no que diz respeito às mulheres.

Mas, afinal de contas, o que é envelhecer? Será que as mudanças ao 
longo da vida, em direção à velhice, são suaves e contínuas ou abruptas, dependendo do estágio desenvolvimental vivido?

As pessoas que pesquisam o desenvolvimento do ciclo vital têm debatido e continuam a debater sobre quais seriam as respostas certas a essas questões, sem, no entanto, chegarem a um entendimento conclusivo. Temos as que preconizam a predominância da genética e/ou fatores biológicos e as que argumentam em favor da primazia das experiências e do ambiente (social, cultural, geográfico, etc.) (Konner, 1982). A psicologia do desenvolvimento, atualmente, ao menos aceita a idéia de que cada uma dessas fontes de transformações tem um papel crucial na interação uma com a outra na especificação do crescimento e da mudança (Scarr; McCartney, 1983).

Apesar de tudo e dos esforços, pouco se sabe ainda das interações que se estabelecem. No entanto, pelo menos em parte, já é aceito que as influências genéticas declinam na medida em que as pessoas vão vivendo e vão assumindo maior preponderância as vivências sociais e culturais (Plomin; McClearn, 1990).

Outro aspecto dessa discussão é que fica difícil responder sobre o que seja o envelhecimento. Dependendo da visão mais biologicista ou social, a resposta pode vaiar enormemente. No contexto, aqui trabalhando, considerase que toda a população faz parte do processo de envelhecimento desde o momento de seu nascimento. A idade constitui-se um dos mecanismos básicos que a sociedade utiliza para distribuir diferentes status e papéis aos indivíduos. $\mathrm{O}$ processo de envelhecimento delimita as mudanças individuais e sociais ao passar de um nível do ciclo vital a outro. As diferenças que estão nesses níveis ou estágios refletem a concepção sobre a idade que cada sociedade tem em um determinado momento histórico (Rodríguez, 1994).

Em todas as sociedade, a vida se divide em unidades socialmente relevantes e o " ( . . . ) tempo biológico se transforma em tempo social." (Neugarten; Neugarten) apud Rodríguez (1994, p. 3). Criam-se e sistematizamse distinções baseadas na idade social, sendo que diferentes direitos e responsabilidades são atribuídos de acordo com a idade social.

Rodríguez (1994) aponta que a idade é um agente de mudança social, pois propicia uma longa série de mudanças e transformações, tanto em nível individual como coletivo, que são conseqüência direta do duplo processo de 
envelhecimento (individual e social). Segundo esse autor, as grandes mudanças dos dois últimos séculos estão, por sua vez, provocando modificações importantes na concepção e definição de idade.

Varia a definição dos diferentes estádios ou níveis de idade social, assim como a dos papéis e status associados a cada um deles. Existe, portanto, uma interação mútua e contínua entre o processo de envelhecimento e a mudança social. Nenhum desses dois processos pode ser entendido totalmente sem o outro.

Dentro dessa mesma linha de pensamento, também não pode-se entender envelhecimento ou uma já assumida velhice, sem associar os conceitos de gênero, classe social, etnia, etc., que são especificações dos contextos social, cultural e histórico.

Aqui, adentra-se ainda mais nas especificações e concretudes do envelhecer: discute-se um pouco a questão do casamento, do amor e do sexo, no período da vida em que as pessoas são já consideradas como estando na velhice. Quando é isso?

No Brasil, a idade de 60 anos marca o início da velhice, em termos cronológicos, ficando assim estabelecido pela Organização da Nações Unidas (ONU) para os países em desenvolvimento, devido às dificuldades sócioeconômicas dos mesmos (Corrêa, 1996). Esta etapa da vida caracteriza-se por uma diversidade de fatores: o processo biológico, que é influenciado pela nutrição, estilo de vida e ambiente, além das causas genéticas (Busse; Blazer, 1992); o fenômeno social e cultural, assim como uma realidade subjetiva e comportamental (Ballesteros, 1994).

Para tratar de casamento, amor e sexo, faz-se necessário que seja introduzido, pelo menos, mais um conceito básico: o de gênero. Este conceito se refere à contraposição que autores fazem ao conceito de sexo, que tem conotação nitidamente biológica e que indica que a pessoa nasceu e foi indicada como sendo macho ou fêmea. $\mathrm{O}$ conceito de gênero, que está relacionado às diferenças sexuais, não é um conceito biológico, mas sim aponta para as construções culturais sobre o que é ser homem ou mulher. "O gênero depende de como a sociedade vê a relação que transforma um macho em um homem e uma fêmea em uma mulher ( . . . ) A construção cultural do gênero é evidente 
quando se verifica que ser homem ou ser mulher nem sempre supõe o mesmo em diferentes sociedades ou em diferentes épocas." (Strey, 1998, p. 183).

\section{Um Estudo Sobre Velhice e Casamento.}

Para discutir sobre casamento, sexo e amor na velhice, dentro dos padrões analisados acima, nada melhor do que tomar um estudo concreto, dentro de uma realidade urbana brasileira, para explorarmos as idéias sobre a relação que existe entre esta fase da vida e a vivência destas relações íntimas de afeto e convivência.

Levando em conta idéias como estas apresentadas, o PSICOGERON * realizou uma pesquisa para conhecer a visão do casamento do homem e da mulher idosos, abrangendo o nível de satisfação e as mudanças acontecidas na sexualidade da velhice.

Toma-se o termo casamento como uma união entre duas pessoas de sexos diferentes, legalizada ou não, as quais se dispuseram a construir uma existência conjunta. Esta relação caracteriza-se pelas pessoas possuírem interesses comuns, seja financeiro, sexual e afetivo, assim como um mesmo objetivo de vida.

Os resultados de pesquisa até agora, compõe-se de dados levantados em uma amostra de 30 pessoas idosas casadas, retratando uma parte da realidade da cidade de Porto Alegre/RS. As pessoas idosas concentram-se em uma faixa de idade média de 68 anos (60 a 81 anos), com nível de escolaridade médio e superior. $\mathrm{O}$ fato de serem bastante escolarizadas, diz que são pessoas mais facilmente encontradas nas camadas médias urbanas, o que não quer dizer que todas as pessoas idosas das cidades tenham um bom nível de escolaridade, principalmente no que diz respeito às mulheres, como será visto adiante. A maioria delas teve no mínimo dois filhos (ou filhas) e dizem praticar a religião católica.

Utilizou-se para a coleta de dados um questionário. Este foi elaborado a

\footnotetext{
*Grupo de Pesquisas e Estudos sobre o Envelhecimento dentro do campo da Psicologia Social, inserido no Grupo de Trabalho e Relações de Gênero coordenado pela Prof ${ }^{a} \operatorname{Dr}^{\mathrm{a}}$ Marlene Neves Strey no Pós-Graduação da Faculdade de Psicologia da PUCRS.
} 
partir de questões trazidas por pessoas idosas de ambos os sexos em entrevistas anteriores, as quais tiveram o objetivo de levantamento de itens para a montagem do instrumento de pesquisa.

Os resultados aqui apresentados estão sujeitos a mudanças, pois tem-se a intenção de alcançar uma abrangência mais diversificada em relação às camadas sociais, ao nível de instrução e ao número de participantes. Sendo assim, somente pode-se falar de uma tendência, mas que, cotejada com a literatura existente sobre o tema, se apresenta como bastante coerente e esperada.

O motivo principal que levou essas pessoas a casarem-se foi o fato de quererem constituir uma família, o que deixa implícito o desejo de terem filhos/ as. No entanto, agora, nesta etapa da vida, a família restringe-se ao casal, visto que seus/suas filhos/as já constituíram suas próprias famílias ou ao menos saíram de casa, isto é, têm as suas vidas independentes de seus pais, já idosos. Outro motivo apontado na pesquisa que os fez casarem-se, foi a aquisição de status e respeito frente à sociedade. Verifica-se, ainda, que um percentual elevado dessas pessoas estava muito satisfeito com o seu casamento e, principalmente, com a sua família.

De certa forma, acredita-se que os estereótipos foram cumpridos, pois o período pós-guerra promoveu uma intensa campanha em termos mundiais, sobre a importância da família e do casamento, com o aval e o reforço das ciências (entre elas a Medicina, a Psiquiatria, a Psicologia e a Pedagogia). Propagou-se, exaustivamente, a imagem estereotipada do lar harmônico, da família feliz e acentuaram-se as infelicidades e problemas de que são vítimas as crianças abandonadas pela não formação do lar, ou pela desestruturação do mesmo. A mulher brasileira da época, bombardeada por toda essa ideologia européia e estadunidense, pensou a identidade feminina a partir do marido, da casa e da criação dos filhos, assumindo o papel de esposa, de dona-de-casa e de mãe. Ela, do período pós-guerra, principalmente, e a de camada média urbana, de cidades grandes e medianas, aceitou para si as responsabilidades pelo bom andamento de sua casa, êxito e felicidade do marido, assim como pelo saudável desenvolvimento das crianças. $\mathrm{O}$ casamento estruturado passou a ser visto como um importante objetivo da maioria das mulheres, assim como ter filhos era a sua realização maior. Essas idéias coincidem com as das pessoas 
idosas de ambos os sexos pesquisadas, sendo apontado o fato de que é a mulher que conserva mais o casamento. Cumpre-se, dessa forma o estereótipo de gênero que vê a mulher como cuidadora do bem-estar psicossocial da família. A construção da identidade na mulher apoiou-se, durante muitos anos, na socialização que lhe foi imposta pelas tarefas domésticas, como esposas e como mães, e isso deu sentido a suas vidas (Strey, 1997). Assim, as mulheres mais velhas de hoje sempre pensaram que essas tarefas eram de sua total responsabilidade.

Neste estudo percebeu-se o casamento como um dos constituintes da identidade, sendo importante para a manutenção da integridade pessoal no processo de envelhecimento. Uma casa impecável, um marido bem-sucedido, uma esposa cuidadora e filhos fortes, felizes e saudáveis foi tudo o que apareceu como desejo de construção de uma família no casamento. Este foi o modelo reproduzido pelas camadas médias urbanas, como aconteceu com os elementos pesquisados e isso se mantém na velhice.

Quanto à sexualidade, as respostas de nossos sujeitos foi de que, em número expressivo, estavam muito satisfeitos. Convém ressaltar que são pessoas que possuem uma média de 40 anos de convivência no casamento. Além disso, embora tenham afirmado não terem relações sexuais muito freqüentes, comparando com a época de quando eram mais jovens, essas pessoas dizem sentir-se satisfeitas com as relações sexuais atuais. A menor frequiência não é por não sentirem prazer, mas por limites do próprio processo de envelhecimento e pelas doenças que apareceram com a velhice.

Outras pesquisas com pessoas idosas demonstraram que há uma dificuldade em responder às questões sobre a sexualidade. Mesmo que nossos pesquisados tenham respondido quanto à satisfação e freqüência da relação sexual, tanto os homens como as mulheres não assinalaram a questão do sexo como importante no casamento. A resposta mais comum foi que com o passar dos anos tanto os homens como as mulheres ficavam mais companheiros e gostavam das mesmas coisas. O sexo não foi visto como importante e sim a amizade. Hoje, na velhice, muitos casais buscam uma afeição mais atualizada de sua vida íntima. Mas sexo nessa fase é um assunto ainda muito encoberto (Rio Grande do Sul, 1997; Fraiman, 1994). Assim que para um número grande 
de pessoas idosas, a sexualidade não é um fator crucial da vida.

As pesquisas sobre casamentos duradouros, como é o caso desta amostra, salientam que o componente central de sustentação de um casal durante os momentos difíceis é a amizade, que se impõe à genitalidade naquilo a que o sexo se refere. Pode-se pensar que as dificuldades sexuais apontadas pelas pessoas idosas sejam minimizadas pelo companheirismo e pela amizade do dia-a-dia, além do que já apontamos em relação aos motivos que as levaram a casar. Atualmente, embora todas tenham casado formalmente, a idéia quase unânime é de que o casamento no papel não é o mais importante e sim a relação. Aqui vemos as transformações sociais incidindo sobre as idéias individuais. As "revoluções" que explodiram a partir da década de sessenta de certa forma não só ajudaram a formar a mentalidade dos adultos e jovens de agora, mas levaram a um redirecionamento às pessoas mais velhas, que já podem pensar a união entre um homem e uma mulher fora da instituição formal (ou sacramento para as mais religiosas) do matrimônio.

A preocupação com a manutenção da saúde foi mais apontada pelas mulheres, embora ambos sintam-se saudáveis. Permanecer em atividade, fazendo algo que seja do seu interesse, é saudável e mantêm a relação com o trabalho, parte importante na constituição de suas identidades.

Manter uma vida própria apareceu pelo desejo manifestado por essas pessoas de não quererem morar com os filhos e nem cuidar de netos. O casal idoso une-se na expectativa de manter a vida a dois, o casamento, como resistência e manutenção da identidade construída pela relação. Estas pessoas, embora cumprindo alguns estereótipos, os quais parecem não questionar, dão sinais de que estão satisfeitas com o que conseguiram até o momento atual.

\section{Referências Bibliográficas}

1 BALLESTEROS, R. F. (Org.). Evaluación conductual hoy - un enfoque para el cambio en psicología clínica y la salud. Madrid, Pirámide, 1994.

\section{BUSSE, E. W.; BLAZER, D. G. (Eds.). O Mito, História e Ciência do}

Envelhecimento. Porto Alegre, Artes Médicas, 1992. 
3 CORRÊA, A. C. De O. Envelhecimento, Depressão e Doença de Alzheimer. Belo Horizonte, Health, 1996.

4 FRAIMAN, A. P. Sexo \& Afeto na Terceira Idade. São Paulo, Editora Gente, 1994.

5 IBGE. Anuário Estatístico do Brasil 1996. Rio de Janeiro, 1997.

6 INSERSO/INSTITUTO DE LA MUJER. Mujeres mayores. Madrid, Ministerio de Asuntos Sociales, 1994.

7 KONNER, D. A. The Tangled Wing: biological constraints on the human spirit. New York, Harper \& Row, 1982.

8 LIMA, Suzana Limeira; STREY, Marlene Neves. O Que é Ser Mulher: um estudo de gênero. In: INTERNATIONAL CONGRESS WOMEN, WORK, HEALTH, 2., Rio de Janeiro, 1999.

9 PLOMIN, R.; McCLEARN, G. E. Human Behavioral Genetics of Aging. In: BIRREN, J. E.; SCHAIE, K. W. (Eds.). Handbook of the Psychology of Aging. San Diego, Academic Press, 1990. p. 67-78.

10 RIO GRANDE DO SUL, Conselho Estadual do Idoso. Os Idosos do Rio Grande do Sul: estudo multidimensional de suas condições de vida: relatório de pesquisa. Porto Alegre, CEI. 1997

11 RODRÍGUEZ, Josep A. Envejecimiento y familia. Madrid, Siglo XXI, 1994.

12 SCARR, S.; McCARTNEY, K. How People Make their Own Environments: a theory of genotype environment effects. Child Development, Chicago, 54, p. 424-435, 1983.

13 STREY, Marlene Neves. A Mulher, seu Trabalho, sua Família e os Conflitos. In: STREY, M. N. (Org.). Mulher: estudos de gênero. São Leopoldo, Editora UNISINOS, 1997.

14 STREY, Marlene Neves. Gênero. In: JACQUES, M. G. C.; STREY, M. N. et al. (Orgs.). Psicologia Social Contemporânea. Petrópolis, Vozes, 1998.

15 VAINFAS, R. Casamento, Amor e Desejo no Ocidente Cristão. São Paulo, Ática, 1986. 
16 VERAS, R. País Jovem com Cabelos Brancos: a saúde do idoso no Brasil.

Rio de Janeiro, Relume-Dumará, UERJ, 1994.

17 WOLF, Naomi. El mito de la belleza. Barcelona, Emecé, 1991. 